\title{
Commentary \\ Establishing the Irish Critical Care Trials Group: 'who wins in battle makes many calculations before the battle is fought'
}

\author{
Brian O'Brien and Dermot Phelan
}

Department of Intensive Care Medicine, The Mater Misericordiae University Hospital, Eccles Street, Dublin 7, Ireland

Corresponding author: Brian O'Brien, drbobrien@hotmail.com

Published: 9 October 2008

Critical Care 2008, 12:183 (doi:10.1186/cc7014)

This article is online at http://ccforum.com/content/12/5/183

(c) 2008 BioMed Central Ltd

See related research by the Irish Critical Care Trials Group, http://ccforum.com/content/12/5/R121

\begin{abstract}
Quality research, requiring large numbers of participants, in the intensive care unit (ICU) population requires multicentre collaboration. Although logistically challenging, this methodology reduces the influence of individual units and has greater validity and broader relevance to patients and practitioners. The nascent Irish Critical Care Trials Group opens additional such opportunities. In the accompanying epidemiologic study, the group present data gathered over 10 weeks of 2006 describing 1,029 patients, from 10 Irish ICUs representing over one-half of Ireland's critical care bed capacity. The data depict a busy service, with $78 \%$ of admissions being emergent and with a moderately high (7\%) readmission rate. While recognising that there were missing data, the outcomes in organ failure and sepsis - where international definitions exist - and the ICU survival rate (83\%) were consistent with international standards. The achievement of this planned first epidemiological step lays the foundation for the conduct of prospective scientific studies. These studies might occur in Ireland or in cooperation with other audit/scientific groups such as the UK's Intensive Care National Audit and Research Centre, the European Critical Care Research Network, or others. This brings us a small step closer to the prospect of global, high-volume studies in critical care.
\end{abstract}

Who wins in battle makes many calculations before the battle is fought.

(Sun Tzu, The Art of War, c.500 BC)

The challenge of conducting high-quality clinical studies in the critically ill population is widely recognised. Heterogeneity in patient populations and clinical practice, diagnostic uncertainty, concerns with consent, and the overlapping nature of the presenting illnesses are amongst the inherent difficulties. Influential studies in this population therefore increasingly involve multicentre, collaborative efforts using rigorously defined inclusion criteria and outcome measures - such projects aim to obviate the aforementioned difficulties and to reduce the influence of individual intensive care units (ICUs) and case-mix variations on the findings. Ultimately, the quality of the data justifies the logistical challenge involved. For this reason, the recent article from the newly-formed Irish Critical Care Trials Group is a welcome announcement of a further such alliance [1].

The data presented describe 1,029 patients admitted to ICU services in a 10-week period in 2006, covering a slight majority of all ICU beds in Ireland. The data include national specialist centres and university teaching hospitals, as well as regional units. The overall pattern depicts a busy service, with $78 \%$ of admissions being emergent in nature, a mean Sequential Organ Failure Assessment score of 5.4, and 70\% of patients needing mechanical ventilation. Previous research in Ireland - showing an ICU bed occupancy rate of $97 \%$, an unscheduled discharge rate of $23 \%$, and frequent cancellation of elective surgery - is consistent with this pattern [2]. The ICU readmission rate of $7.5 \%$ is perhaps attributable to these service realities - as indeed may be the failure to collect data in four of the 14 units that entered the study, including $23 \%$ of relevant patients.

While accepting that the missing patient data compromise the validity of the findings, the outcomes nonetheless appear compatible with international standards and indeed are broadly indicative of the success of modern intensive care medicine. More than $80 \%$ of patients survived their ICU stay. The outcomes in the subgroups are more striking: over $75 \%$ of readmitted patients survived and, of the 93 patients with five or six systems failing on admission, just over one-half survived.

Compatibility with international outcomes is perhaps most evident from those diagnostic categories where standard,

ICU = intensive care unit; RIFLE = Risk-Injury-Failure-Loss-End stage. 
consensus definitions are established. For severe sepsis, the ICU mortality of $24 \%$ compares with a reported $35 \%$ in England, Wales and Northern Ireland for severe sepsis in the first 24 hours [3]. For acute lung injury/acute respiratory distress syndrome, the Irish mortality was 32\% - and the Irish Critical Care Trials Group has previously shown that this is consistent with modern international studies in the protective ventilation era [4]. Although the numbers are relatively small $(n=289)$, an ICU mortality of $38 \%$ for renal failure compares unfavourably with the hospital mortality of $26.3 \%$ reported by Hoste and colleagues using the same criteria [5]. Nonetheless, the study arguably further validates these RIFLE (RiskInjury-Failure-Loss-End stage) descriptors as outcome predictors in acute renal dysfunction [5].

Certain shortcomings are inevitable in this research format. Seasonal and regional variations cannot be detected as data from a short collection period are pooled together. Nothing can be inferred about decision-making processes. The use of ICU mortality alone as a measure of outcome is not ideal, and more meaningful outcome assessment tools including hospital mortality should be utilised in future projects [6]; for example, patients who were refused readmission and who might have gone on to die in hospital wards will appear as survivors in such a crude analysis. Future scientific publications should also avoid the irritation of new data introduction in the discussion of the findings.

The value of the present data will be more fully realised when the Irish Critical Care Trials Group produces further, hypothesis-testing studies. Having taken advice from the ANZICS Critical Care Trials Group, the Irish Critical Care Trials Group set out to achieve this epidemiological study to provide baseline information for research planning. The data provide insight into disease prevalence (for example, of acute respiratory distress syndrome), and enable planning for the study duration and resource allocation once power analysis has indicated the size of the study population required. The demonstration of the willingness of team members to cooperate and of the capacity of information systems to gather and collate such information is a further key to such studies and collaborations.

The authors identify an urgent requirement for audit resources to maintain the ambition shown by this study. Participation in the UK's Intensive Care National Audit and Research Centre would be one option, opening up the possibility of a UK/Irish database. Alternatively, broader international collaborations might work. The ability demonstrated by the Irish Critical Care Trials Group study to establish a research ethos that straddles the relatively contentious border linking the Irish Republic with the United Kingdom is scientifically encouraging.

\section{Competing interests}

The authors declare that they have no competing interests.

\section{References}

1. The Irish Critical Care Trials Group: Intensive care for the adult population in Ireland: a multicentre study of intensive care population demographics. Crit Care 2008, 12:R121.

2. Charles R, Marsh B, Carton E, Power M, Motherway C, Claffey L, Crowley K, O'Hare B, O'Leary E, Ryan T: Accessibility of intensive care facilities in Ireland to critically ill patients. Ir Med J 2002, 95:72-74.

3. Padkin A, Goldfrad C, Brady AR, Young D, Black N, Rowan K: Epidemiology of severe sepsis occurring in the first $24 \mathrm{hrs}$ in intensive care units in England, Wales, and Northern Ireland. Crit Care Med 2003, 31:2332-2338.

4. Irish Critical Care Trials Group: Acute lung injury and the acute respiratory distress syndrome in Ireland: a prospective audit of epidemiology and management. Crit Care 2008, 12:R30.

5. Hoste EA, Clermont G, Kersten A, Venkataraman R, Angus DC, De Bacquer D, Kellum JA: RIFLE criteria for acute kidney injury are associated with hospital mortality in critically ill patients: a cohort analysis. Crit Care 2006, 10:R73.

6. Black N, Jenkinson C, Hayes J, Young D, Vella K, Rowan K, Daly K, Ridley S: Review of outcome measures used in adult critical care. Crit Care Med 2001, 29:2119-2124. 